\title{
Qualidade da água subterrânea para irrigação na bacia hidrográfica do Rio Piauí, em Sergipe
}

\author{
Julio R. A. de Amorim ${ }^{1}$, Marcus A. S. Cruz ${ }^{1} \&$ Ronaldo S. Resende ${ }^{1}$
}

\begin{abstract}
RESU MO
0 uso de água subterrânea para fins agrícolas tem-se intensificado no Estado de Sergipe, sobretudo na região de maior escassez de águas superficiais; no entanto, a irrigação ainda está restrita a pequenas áreas, como hortas familiares, justificado, em parte, pela ausência de estudos de caracterização hídrica, incluindo disponibilidade e qualidade das águas subterrâneas, que permitam o conhecimento da distribuição espacial das fontes de água viáveis para uso. Avaliaram-se os riscos potenciais relativos à salinização e sodificação de solos, à toxicidade de íons específicos às culturas e à obstrução em sistemas de irrigação localizada, a partir de dados secundários de 278 poços local izados na bacia hidrográfica do Rio Piauí, considerando-se os critérios de restrição ao uso da água para irrigação estabelecidos pela FA O. Mapas de risco foram gerados por procedimentos de krigagem ordinária, para as variáveis indicadoras de qualidade da água, que possibilitaram a visualização do comportamento espacial das águas na bacia. Verificou-se que as águas subterrâneas apresentam boas condições para uso na irrigação, principalmente na porção centro-litorânea da bacia, visto que houve tendência de aumento na concentração de sais das águas no sentido centro-cabeceiras.
\end{abstract}

Palavras-chave: recursos hídricos subterrâneos, indicadores de qualidade da água, análise espacial, krigagem

\section{Groundwater quality for irrigation purposes in Piauí River Basin in the State of Sergipe, Brazil}

\begin{abstract}
Groundwater use for agricultural purposes has been intensified in the State of Sergipe, mainly in the regions with more serious water shortage from surface sources. However, irrigation is still restricted to small areas like home gardens. In part, this problem is due to lack of studies on characterization of water resources, including availability and quality of groundwaters, detecting the spatial distribution of viable sources of groundwater for different uses. The potential hazards related to soil salinity and sodicity, toxicity of specific ions for crops, and clogging of components of microirrigation systems were evaluated. Physicochemical data of water from 278 deep wells located in Piauí River Basin, in the State of Sergipe, Brazil, were used considering the FAO restriction criteria for irrigation purposes. Maps of spatial distribution of groundwater quality indicators in the watershed were prepared by ordinary kriging procedures. Groundwaters show ed good quality for irrigation use, mainly in the center-downstream portion of the river basin. There was a trend in increasing the salt concentration in water from the coast to inland in the Piauí River Basin area.
\end{abstract}

Key words: groundwater resources, water quality indicators, spatial analysis, kriging 


\section{INTRODUÇÃO}

O Estado de Sergipe, situado na Região Nordeste do Brasil, está parcialmente incluído no chamado Polígono das Secas, caracterizado como uma região com extrema irregularidade na distribuição das precipitações pluviais, o que gera restrições à disponibilidade de água para os múltiplos usos (Silva, 2004). Neste cenário de escassez hídrica se intensifica a procura pelos mananciais subterrâneos que, na maioria das vezes, têm sua gestão dificultada pela ausência de informações sobre quantidade e qualidade dos recursos explotados (Hirata et al., 2007). Dentre os usos dados à água subterrânea no Estado de Sergipe se destacam abastecimento doméstico, irrigação e dessendentação de animais (Bomfim et al., 2002). O uso da água subterrânea para irrigação de culturas se apresenta como alternativa viável para a sustentabilidade econômica das atividades agrícolas na região.

A bacia hidrográfica é considerada a unidade de planejamento na gestão dos recursos hídricos (Porto \& Porto, 2008). Assim, a espacialização de características físico-químicas das águas subterrâneas proporciona a geração de informações que podem subsidiar o processo de tomada de decisão relacionado à adoção de políticas de uso dos recursos hídricos e ao processo de outorga de água para projetos de irrigação, além de constituir diretriz para instituições de crédito agrícola. Neste aspecto, faz-se necessário um diagnóstico dos riscos potenciais associados à qualidade da água que poderão acarretar problemas relacionados principalmente à degradação dos solos pela salinização e/ou ao entupimento em sistemas de irrigação localizada, caso não se adotem medidas de correção ou mitigação (Medeiros et al., 2003; Oliveira et al., 2005; Ribeiro et al., 2005; Rodrigues et al., 2007; Smith, 2008). O quadro atual dos solos afetados por sais em escala mundial - com uma estimativa de que quase 400 milhões de hectares de terras agricultáveis estejam afetados, em algum grau, pela salinização - vem aumentando progressivamente com a intensificação das práticas de irrigação (Amorim et al., 2008).

O tipo de armazenamento das águas (aquíferos livres, confinados ou fraturados), o clima e a natureza geológica (influência litológica na composição química da água) são os principais fatores que interferem no processo de salinização causado pelo uso das águas subterrâneas no Nordeste brasileiro (Cruz \& Melo, 1969). O processo de avaliação da adequação de determinada água para irrigação deve considerar: riscos de salinização, sodificação e alcalinização por carbonatos para o solo; aspectos tóxicos em relação a cloreto e sódio para as plantas; e danos ao sistema de irrigação pela alta concentração de sais de baixa solubilidade (Andrade Júnior et al., 2006).

A determinação do potencial de uso da água para fins de irrigação deve considerar, além dos teores dos sais, os efeitos específicos do íon sódio na permeabilidade do solo e sua toxicidade para as plantas (Amorim et al., 2008; Qadir et al., 2008). A relação de adsorção do sódio (RAS) é utilizada como medida do risco de sodicidade, visto que ela expressa a relação entre as concentrações dos íons sódio, cálcio e magnésio - que compõem os sais de maior influência nas condições de infiltração da água no solo - podendo ainda ser correlacionada com a RAS do solo depois de atingido o equilíbrio dinâmico (Andrade Júnior et al., 2006). Recomenda-se, também, o uso da condutividade elétrica da água de irrigação (CEa) associada à RAS para avaliação do risco de redução da capacidade de infiltração de água no solo, considerando-se que os sais presentes na solução do solo têm efeito floculante, oposto ao efeito dispersante do sódio trocável; logo, para um mesmo valor de RAS, o risco de sodicidade será tanto menor quanto maior for a CEa (Amorim et al., 2008; Andrade Júnior et al., 2006; Ayers \& Westcot, 1994).

A presença de sais na água subterrânea está diretamente relacionada com sua capacidade de dissolução e com o tipo de substrato com o qual esta tem contato; portanto, o principal fator determinante é a geologia da região (Amorim et al., 2008; Silva Júnior et al., 1999). Aquíferos fraturados apresentam, geralmente, águas explotadas com maiores teores de sais que os granulares, fato que ocorre como resultado dos maiores períodos de contato, da falta de circulação das águas e dos tipos de rocha predominantes (Bonfim et al., 2002).

O presente trabalho constitui parte de um estudo que está reunindo e consolidando dados de poços tubulares profundos no Estado de Sergipe, existentes em bases de dados distintas, em um único banco de dados georreferenciados, baseado em Sistema de Informações Geográficas - SIG, após análise crítica das variáveis componentes. O estudo visa estruturar informações que sirvam de subsídio para um planejamento melhor do manejo das águas subterrâneas no Estado de Sergipe atendendo, desta forma, às determinações da Política Nacional de Recursos Hídricos.

Assim, este trabalho objetivou analisar e caracterizar a distribuição espacial de variáveis de qualidade da água subterrânea que funcionem como indicadores dos potenciais riscos ao uso deste recurso para irrigação na bacia hidrográfica do Rio Piauí, em Sergipe.

\section{MATERIAL E MÉTODOS}

A região de estudo compreende a bacia hidrográfica do Rio Piauí, situada na porção centro-sul do Estado de Sergipe e localizada entre as latitudes $10^{\circ} 41^{\prime} 05^{\prime \prime}$ e $11^{\circ} 30^{\prime} 36^{\prime \prime} \mathrm{S}$ e longitudes $38^{\circ} 01$ ' $50^{\prime \prime}$ e $37^{\circ} 11^{\prime} 17^{\prime}$ W. Esta bacia apresenta área de $4.314 \mathrm{~km}^{2}$, cujo rio principal, o Piaú, possui cerca de $150 \mathrm{~km}$ de extensão, desembocando no oceano Atlântico (Sergipe, 2004). Na Figura 1, se apresentam a bacia hidrográfica e sua localização.

A Bacia do Rio Piauí apresenta três climas predominantes: Litoral Úmido, Agreste e Semiárido, este último apenas em sua porção noroeste, a qual se insere no Polígono das Secas. A temperatura média anual se situa em torno dos $24,5^{\circ} \mathrm{C}$. A precipitação média anual é de $1.200 \mathrm{~mm}$, com bastante variação atingindo, próximo ao litoral, $2.000 \mathrm{~mm}$ e, na região do Polígono das Secas, menos de $800 \mathrm{~mm}$. As precipitações ocorrem no período de fevereiro a setembro, com variações dentro deste período de acordo com a região da bacia, concentrando-se, na sua maioria, no intervalo dos meses de março a julho (Sergipe, 2004). Existe grande vari- 


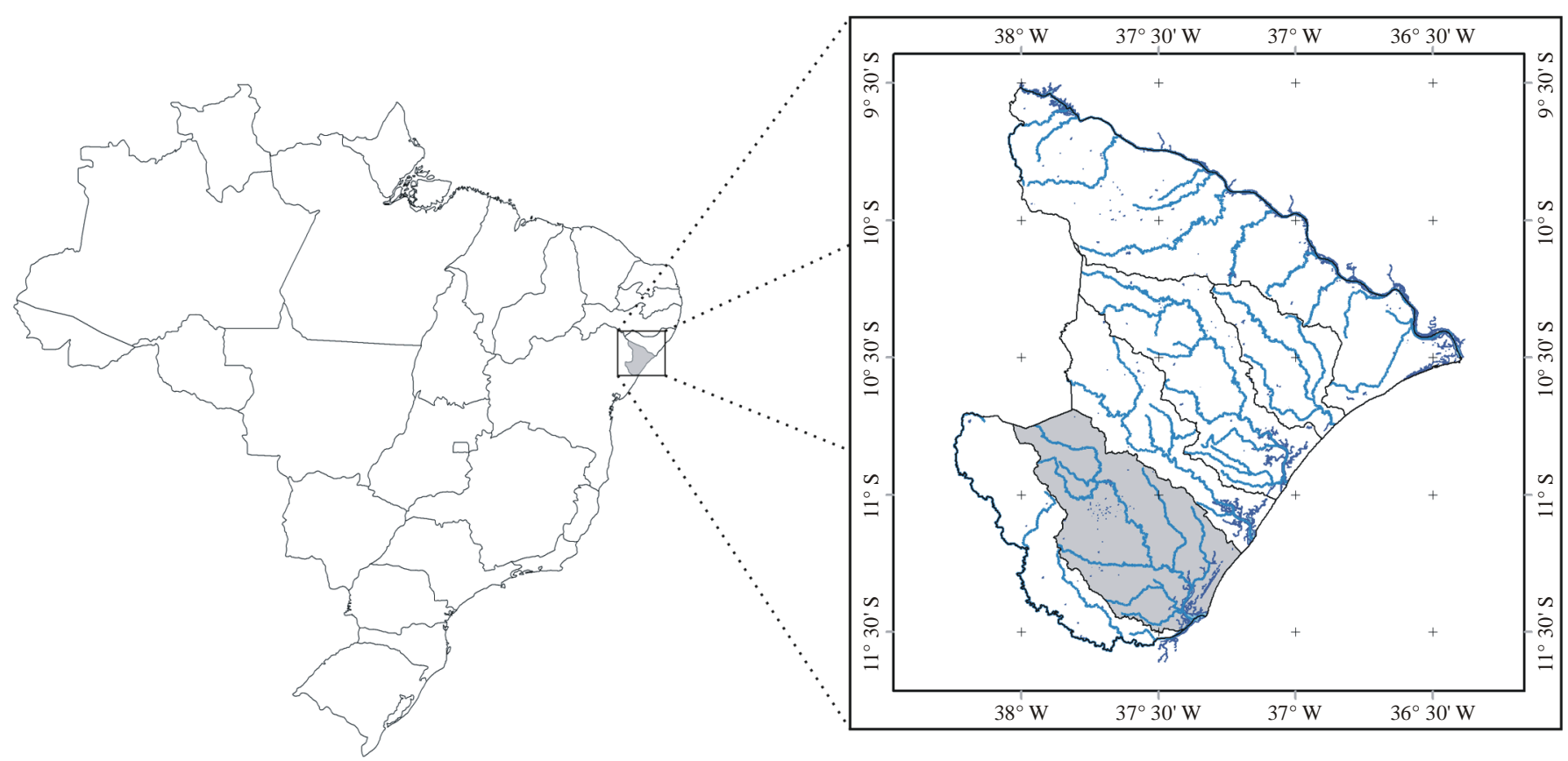

Figura 1. Localização da bacia hidrográfica do Rio Piauí no Estado de Sergipe

abilidade de cobertura vegetal na bacia, com campos limpos e sujos, capoeira, caatinga, cerrado, higrófilas, vestígios de mata e mata. Esta bacia abrange terras dos municípios de Lagarto, Estância, Riachão do Dantas, Salgado, Boquim, Aruá, Itabaianinha, Simão Dias, Santa Luzia do Itanhy, Pedrinhas, Indiaroba, Umbaúba, Itaporanga d'Ajuda, Tobias Barreto e Poço Verde. As atividades de maior importância socioeconômica na bacia são: agricultura, com a produção de laranja, limão, maracujá, mandioca, mamão, tangerina, milho, feijão e coco; pecuária, destacando-se as criações de bovinos, ovinos, suínos, equinos e galináceos; e mineração, com a exploração de argilas, areia, brita, cal, granito e águas minerais (Sergipe, 2004).

A composição geológica da bacia do Rio Piauí configura a predominância de rochas do tipo cristalino, principalmente em sua porção centro-noroeste, associadas a formações calcárias em seu extremo noroeste. Nesta região, o armazenamento das águas subterrâneas ocorre nas fissuras, isoladamente ou intercomunicadas, caracterizando os aquíferos dos tipos fissural, fissural-cárstico e fissural muito fraturado. Na região centro-leste ocorrem domínios sedimentares, com predominância de aquíferos do tipo granular (CPRM, 2007). A distribuição espacial das unidades aquíferas na bacia hidrográfica do Rio Piauí é apresentada na Figura 2.

Para avaliação da qualidade das águas subterrâneas na bacia, analisaram-se as seguintes variáveis: $\mathrm{pH}$, condutividade elétrica, em dS m${ }^{-1}$ a $25^{\circ} \mathrm{C}$, sólidos dissolvidos totais (SDT), em mg L ${ }^{-1}$ a $105^{\circ} \mathrm{C}$, sódio $\left(\mathrm{Na}^{+}\right)$, cálcio $\left(\mathrm{Ca}^{2+}\right)$, magnésio $\left(\mathrm{Mg}^{2+}\right)$, cloreto $\left(\mathrm{Cl}^{-}\right)$, carbonato $\left(\mathrm{CO}_{3}^{2-}\right)$, bicarbonato $\left(\mathrm{HCO}_{3}^{-}\right)$, em $\mathrm{mmol}_{\mathrm{c}} \mathrm{L}^{-1}$, e ferro $(\mathrm{Fe})$ total, em $\mathrm{mg} \mathrm{L}^{-1}$. Além dessas, foram calculados os valores da relação de adsorção de sódio e do índice de saturação de Langelier (ISL), que serão descritos adiante. Obtiveram-se os valores para as variáveis a partir de dados secundários da Companhia de Desenvolvimento de Recursos Hídricos e Irrigação de Sergipe - COHI-

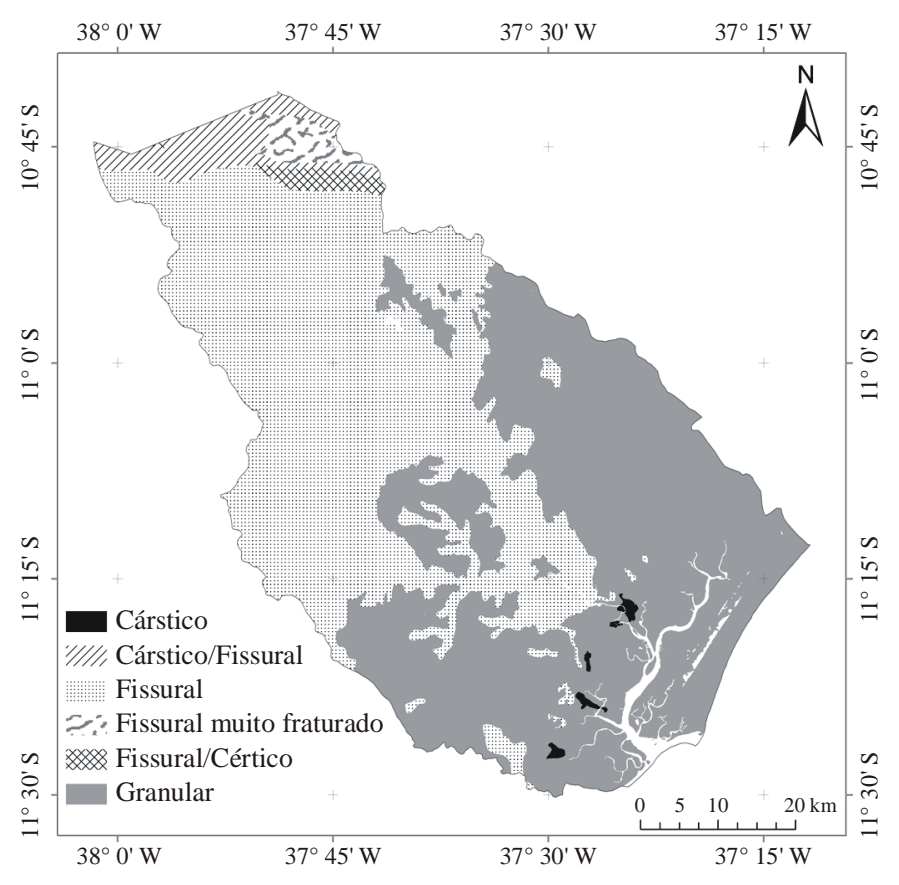

$\overline{\text { Figura 2. Tipos de aquíferos e sua distribuição espacial na bacia hidrográfica }}$ do Rio Piauí, em Sergipe (CPRM, 2007)

DRO, vinculada à Secretaria de Estado da Agricultura e Desenvolvimento Agrário - SEAGRI e da Superintendência de Recursos Hídricos - SRH, órgão vinculado à Secretaria de Estado do Meio Ambiente e dos Recursos Hídricos - SEMARH. Dados de 278 poços tubulares foram disponibilizados e distribuídos na bacia do Rio Piauí, conforme apresentado na Figura 3. Realizou-se análise de consistência dos dados, por meio de gráficos de dispersão e relações conhecidas entre variáveis, como o balanço entre a soma de cátions e ânions, assim como análise exploratória com a estimativa de parâ- 


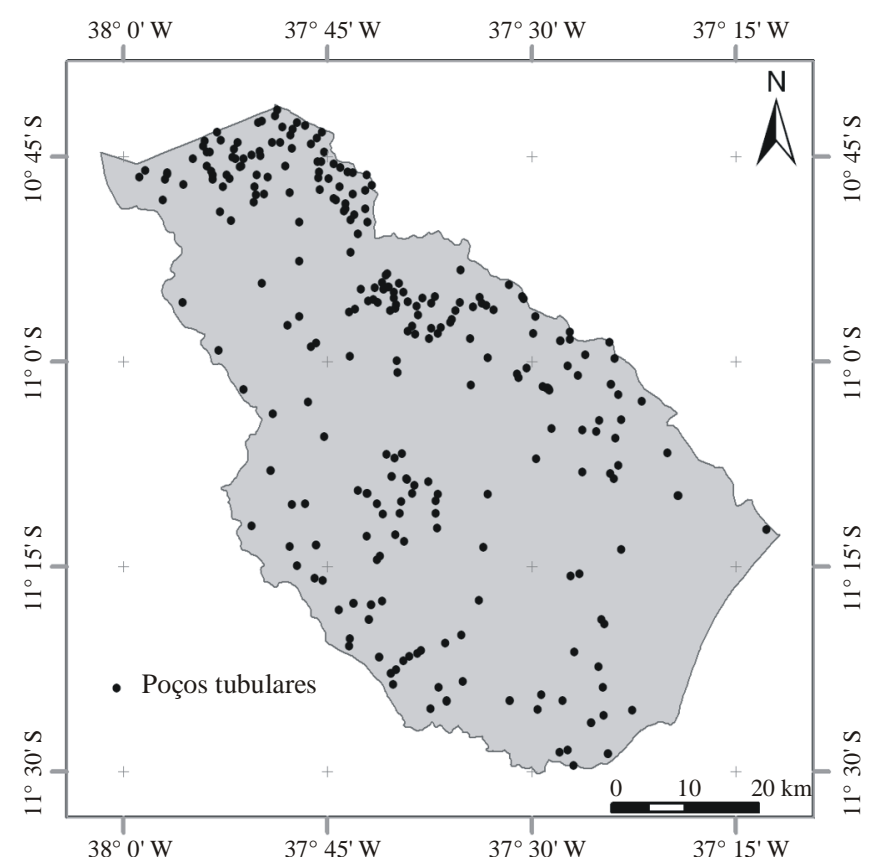

Figura 3. Distribuição espacial dos poços tubulares profundos na bacia hidrográfica do Rio Piauí, em Sergipe

metros de tendência central e dispersão, cujo procedimento resultou na eliminação de alguns dados.

$\mathrm{Na}$ análise da restrição ao uso da água subterrânea para fins de irrigação com base nas variáveis indicadoras de qualidade, consideraram-se os riscos de salinização e sodificação para os solos, de toxicidade de íons específicos para as culturas irrigadas por sistemas de irrigação por superfície e aspersão e de obstrução para os sistemas de irrigação localizada. De acordo com Ayers \& Westcot (1994), foram definidos os limites das classes de restrição. Os intervalos para classificação das águas, segundo os riscos associados ao uso para irrigação, estão apresentados na Tabela 1.

Os riscos de sodificação do solo, isto é, redução da capacidade de infiltração de água no solo pela sodicidade, podem ser avaliados com base na comparação dos valores da RAS com os da CEa, conforme indicado na Tabela 1. A RAS é calculada da seguinte forma (Ayers \& Westcot, 1994):

$$
\mathrm{RAS}=\frac{\mathrm{Na}^{+}}{\sqrt{\frac{\mathrm{Ca}^{2+}+\mathrm{Mg}^{2+}}{2}}}
$$

com as concentrações de $\mathrm{Na}^{+}, \mathrm{Ca}^{2+}$ e $\mathrm{Mg}^{2+}$ expressas em $\operatorname{mmol}_{\mathrm{c}} \mathrm{L}^{-1}$.

A avaliação dos riscos de obstrução em sistemas de irrigação localizada está relacionada principalmente às concentrações de ferro e à precipitação de carbonato de cálcio $\left(\mathrm{CaCO}_{3}\right)$. Esta última pode ser estimada por meio do índice de saturação de Langelier (Amorim et al., 2008; Ayers \& Westcot, 1994; Ribeiro et al., 2005):

$$
\mathrm{ISL}=\mathrm{pH}_{\mathrm{a}}-\mathrm{pH}_{\mathrm{c}}
$$

em que $\mathrm{pH}_{\mathrm{a}}$ é o $\mathrm{pH}$ da amostra e $\mathrm{pH}_{\mathrm{c}}$ se refere ao $\mathrm{pH}$ de equi-
Tabela 1. Classes de restrição ao uso da água para irrigação, segundo

\begin{tabular}{|c|c|c|c|c|c|}
\hline \multirow[b]{2}{*}{ Risco } & \multirow[b]{2}{*}{$\begin{array}{l}\text { Sistema de } \\
\text { Imigação }\end{array}$} & \multirow[b]{2}{*}{ Variáveis } & \multicolumn{3}{|c|}{ Classes de restrição } \\
\hline & & & Nenhuma & $\begin{array}{l}\text { Leve a } \\
\text { Moderada }\end{array}$ & Severa \\
\hline \multirow{2}{*}{ Salinização } & & $\mathrm{CEa}\left(\mathrm{dS} \mathrm{m}^{-1}\right)$ & $<0,7$ & 0,7 a 3,0 & $>3,0$ \\
\hline & & SDT (mg L-1 $)$ & $<450$ & 450 a 2.000 & $>2.000$ \\
\hline \multirow{6}{*}{$\begin{array}{l}\text { Sodificação } \\
\text { (redução da } \\
\text { infiltração de } \\
\text { água no } \\
\text { solo) }\end{array}$} & & RAS $\left(\mathrm{mmol} \mathrm{L}^{-1}\right)^{3 / 2}$ & & CEa $\left(\mathrm{dS} \mathrm{m}^{-1}\right)$ & \\
\hline & & 0 a 3 & $>0,7$ & 0,7 a 0,2 & $<0,2$ \\
\hline & & 3 a 6 & $>1,2$ & 1,2 a 0,3 & $<0,3$ \\
\hline & & 6 a 12 & $>1,9$ & 1,9 a 0,5 & $<0,5$ \\
\hline & & 12 a 20 & $>2,9$ & 2,9 a 1,3 & $<1,3$ \\
\hline & & 20 a 40 & $>5,0$ & 5,0 a 2,9 & $<2,9$ \\
\hline \multirow{5}{*}{$\begin{array}{l}\text { Toxicidade } \\
\text { de íons } \\
\text { específicos } \\
\text { às culturas }\end{array}$} & Superfície & RAS $\left(\mathrm{mmol} \mathrm{L}^{-1}\right)^{1 / 2}$ & $<3,0$ & 3,0 a 9,0 & $>9,0$ \\
\hline & Aspersão & $\mathrm{Na}^{+}\left(\mathrm{mmol}_{\mathrm{c}} \mathrm{L}^{-1}\right)$ & $<3,0$ & $>3,0$ & \\
\hline & Superfície & $\mathrm{Cl}\left(\mathrm{mmol}_{\mathrm{c}} \mathrm{L}^{-1}\right)$ & $<4,0$ & 4,0 a 10,0 & $>10,0$ \\
\hline & Aspersão & $\mathrm{Cl}^{-}\left(\mathrm{mmol}_{\mathrm{c}} \mathrm{L}^{-1}\right)$ & $<3,0$ & $>3,0$ & \\
\hline & Aspersão & $\mathrm{HCO}_{3}^{-}\left(\mathrm{mmol}_{\mathrm{c}} \mathrm{L}^{-1}\right)$ & $<1,5$ & 1,5 a 8,5 & $>8,5$ \\
\hline \multirow{3}{*}{$\begin{array}{l}\text { Obstrução } \\
\text { em sistemas } \\
\text { de irrigação } \\
\text { localizada }\end{array}$} & & $\mathrm{pH}$ & $<7,0$ & 7,0 a 8,0 & $>8,0$ \\
\hline & & Fe total $\left(\mathrm{mg} \mathrm{L}^{-1}\right)$ & $<0,1$ & 0,1 a 1,5 & $>1,5$ \\
\hline & & ISL & $<0,0$ & $>0,0$ & \\
\hline
\end{tabular}
os riscos associados

Fonte: Adaptado de Ayers \& Westcot (1994)

\section{líbrio para $\mathrm{CaCO}_{3}$.}

Valores positivos de ISL $\left(\mathrm{pH}_{\mathrm{a}}>\mathrm{pH}_{\mathrm{c}}\right.$ ) evidenciam tendência à precipitação do $\mathrm{CaCO}_{3}$ com risco de ocorrência de obstrução nos sistemas de irrigação, enquanto valores negativos do índice indicam que o $\mathrm{CaCO}_{3}$ presente na água permanecerá dissolvido (Amorim et al., 2008; Ayers \& Westcot, 1994; Mélo et al., 2008; Ribeiro et al., 2005). O cálculo de $\mathrm{pH}_{\mathrm{c}}$ é realizado utilizando-se a seguinte equação:

$$
\mathrm{pHc}=\left(\mathrm{pK}_{2}-\mathrm{pK}_{\mathrm{c}}\right)+\mathrm{pCa}+\mathrm{p}(\mathrm{Alk})
$$

em que: $\mathrm{pK}_{2}-\mathrm{pK}_{\mathrm{c}}$ é obtido pela soma das concentrações de $\mathrm{Ca}^{2+}, \mathrm{Mg}^{2+} \mathrm{e} \mathrm{Na}^{+}\left(\mathrm{mmol}_{\mathrm{c}} \mathrm{L}^{-1}\right) ; \mathrm{pCa}$, da concentração de $\mathrm{Ca}^{2+}$ $\left(\mathrm{mmol}_{\mathrm{c}} \mathrm{L}^{-1}\right)$; e $\mathrm{p}(\mathrm{Alk})$, da soma das concentrações de $\mathrm{CO}_{3}{ }^{2-}$ e $\mathrm{HCO}_{3}^{-}\left(\mathrm{mmol}_{\mathrm{c}} \mathrm{L}^{-1}\right)$.

Aplicaram-se procedimentos de krigagem ordinária aos dados produzindo-se superfícies interpoladas que representam o comportamento espacial das variáveis de qualidade das águas subterrâneas na bacia. Para esta atividade utilizou-se o módulo GeoStatistical Analyst do software ArcGIS. Os mapas obtidos foram submetidos a um processo de cruzamento e fatiamento, segundo os limites das classes de restrição apresentados na Tabela 1, gerando-se novos mapas com regiões classificadas de acordo com os riscos associados ao uso das águas subterrâneas para irrigação.

\section{RESULTADOS E DISCUSSÃO}

Os principais descritores estatísticos por variável estão apresentados na Tabela 2. Observa-se que houve grande variabilidade nos valores das variáveis, expressa pelos altos valores de coeficientes de variação, excetuando-se para $\mathrm{pH}$. Esta característica é justificada pela distribuição espacial dos poços, com incidência em diferentes formações geológicas, 
Tabela 2. Descritores estatísticos das variáveis indicadoras de qualidade da água subterrânea na bacia hidrográfica do Rio Piauí, em Sergipe

\begin{tabular}{|c|c|c|c|c|c|c|c|}
\hline Variáveis & $\begin{array}{l}\text { Número de } \\
\text { observações }\end{array}$ & Média & Mediana & Valor mínimo & Valor máximo & Desvio padrão & CV (\%) \\
\hline $\mathrm{pH}$ & 278 & 7,49 & 7,56 & 4,57 & 9,34 & 0,69 & 9 \\
\hline CEa & 269 & 1,29 & 0,62 & 0,06 & 11,13 & 1,70 & 132 \\
\hline SDT & 276 & 938,44 & 420,40 & 58,20 & $8.911,20$ & $1.268,63$ & 135 \\
\hline $\mathrm{Cl}^{-}$ & 276 & 9,82 & 2,81 & 0,24 & 112,91 & 16,47 & 168 \\
\hline $\mathrm{HCO}_{3}^{-}$ & 273 & 3,10 & 2,46 & 0,06 & 14,03 & 2,54 & 82 \\
\hline Fe total & 189 & 0,58 & 0,09 & 0,00 & 4,18 & 1,12 & 191 \\
\hline $\mathrm{Ca}^{2+}$ & 274 & 3,36 & 1,50 & 0,07 & 35,27 & 4,84 & 144 \\
\hline $\mathrm{Mg}^{2+}$ & 273 & 2,99 & 1,17 & 0,07 & 42,70 & 4,58 & 153 \\
\hline $\mathrm{Na}^{+}$ & 265 & 7,34 & 2,87 & 0,27 & 69,60 & 10,41 & 142 \\
\hline RAS & 265 & 3,83 & 2,70 & 0,54 & 18,83 & 3,25 & 85 \\
\hline ISL & 273 & $-0,52$ & $-0,43$ & $-4,54$ & 2,11 & 1,10 & 211 \\
\hline
\end{tabular}

produzindo amplo intervalo de variação dos valores para uma mesma variável.

Considerando-se os valores médios, verifica-se que eles se concentraram na classe com restrição leve a moderada para quase todas as variáveis, exceto para o ISL, cujo valor médio $(-0,52)$ se situou na classe sem restrição ao uso (Tabelas 2 e 1), sendo menor do que -0,5, valor de ISL abaixo do qual não há risco de formação de precipitados, de acordo com Ayers \& Westcot (1994) e Medeiros et al. (2003); no entanto, levando-se em consideração os desvios nos valores de cada variável, observa-se também a ocorrência de valores nas classes de restrição "nenhuma" e "severa", para todas as variáveis avaliadas, conforme resultados presentes na Tabela 3. Para o risco de salinização do solo, nota-se que mais de $50 \%$ das águas não apresentaram restrições, tanto para $\mathrm{CEa}$ quanto para SDT; todavia, aproximadamente $11 \%$ para CEa e $12 \%$ para SDT se situaram na classe de restrição severa.

Com base na análise conjunta de RAS e CEa, que avalia o risco de sodificação do solo, ou seja, de redução da capacidade de infiltração de água no solo, verifica-se que a maior frequência de águas se situou na classe de restrição leve a moderada (46,8\%), com aproximadamente $19 \%$ das águas estando incluídas na classe de restrição severa (Tabela 3).

Tabela 3. Distribuição de frequências das variáveis (\%) em cada classe de restrição ao uso da água subterrânea para fins de irrigação na bacia hidrográfica do Rio Piauí, em Sergipe

\begin{tabular}{|c|c|c|c|c|}
\hline Risco & Variável & Nenhuma & $\begin{array}{l}\text { Leve a } \\
\text { Moderada }\end{array}$ & Severa \\
\hline \multirow{2}{*}{ Salinização } & $\mathrm{CEa}$ & 55,4 & 33,5 & 11,2 \\
\hline & SDT & 53,6 & 34,1 & 12,3 \\
\hline $\begin{array}{l}\text { Sodificação } \\
\text { (redução da } \\
\text { infiltração de } \\
\text { água no solo) }\end{array}$ & RAS e CEa & 34,3 & 46,8 & 18,9 \\
\hline \multirow{2}{*}{$\begin{array}{l}\text { Toxicidade na } \\
\text { irrigação por } \\
\text { superfície }\end{array}$} & RAS & 55,5 & 36,6 & 7,9 \\
\hline & $\mathrm{Cl}^{-}$ & 56,9 & 14,1 & 29,0 \\
\hline \multirow{3}{*}{$\begin{array}{l}\text { Toxicidade na } \\
\text { irrigação por } \\
\text { aspersão }\end{array}$} & $\mathrm{Na}^{+}$ & 52,1 & \multicolumn{2}{|c|}{47,9} \\
\hline & $\mathrm{Cl}^{-}$ & 50,7 & \multicolumn{2}{|c|}{49,3} \\
\hline & $\mathrm{HCO}_{3}^{-}$ & 31,5 & 64,5 & 4,0 \\
\hline \multirow{3}{*}{$\begin{array}{l}\text { Obstrução em } \\
\text { sistemas de } \\
\text { irrigação } \\
\text { localizada }\end{array}$} & $\mathrm{pH}$ & 19,4 & 58,3 & 22,3 \\
\hline & Fe total & 50,3 & 36,5 & 13,2 \\
\hline & ISL & 66,3 & \multicolumn{2}{|c|}{33,7} \\
\hline
\end{tabular}

O risco de toxicidade de íons específicos às culturas é avaliado levando-se em consideração, entre outros fatores, o tipo de sistema de irrigação utilizado na aplicação da água. Portanto, para sistemas de irrigação por superfície a maioria das águas subterrâneas não apresentou restrição ao uso em relação aos íons sódio $(55,5 \%)$, avaliado pela RAS, e cloreto $(56,9 \%)$, conforme Tabela 3 . Observa-se, ainda, para sódio e cloreto, que cerca de 8 e de $29 \%$ das águas, respectivamente, incidiram sobre a classe de restrição severa, ou seja, há maior risco quanto à concentração de cloreto; já para sistemas de irrigação por aspersão, as variáveis sódio e cloreto se enquadram em apenas duas classes: sem e com restrição (Tabela 1), verificando-se, neste caso, um equilíbrio na distribuição de frequências das águas, com aproximadamente 48 e $49 \%$ destas com restrição para sódio e cloreto, respectivamente (Tabela 3). Quanto ao íon bicarbonato, houve predominância de águas na classe de restrição leve a moderada $(64,5 \%)$ e pequena quantidade com restrição severa (4\%).

No que se refere aos riscos associados à obstrução em sistemas de irrigação localizada, constatou-se grande variabilidade na distribuição de frequências entre as variáveis analisadas (Tabela 3). Considerando-se pH, por exemplo, nota-se que a maioria das águas dos poços se enquadrou na classe leve a moderada $(58,3 \%)$, com distribuição equilibrada entre as outras duas classes. Para ferro total verificou-se predominância de águas sem restrição ao uso $(50,3 \%)$ e baixa incidência na classe de restrição severa $(13,2 \%)$, embora águas com valor médio de $0,58 \mathrm{mg} \mathrm{L}^{-1}$ (Tabela 2) possam causar problemas de obstrução nos emissores e redução na uniformidade de aplicação de água em sistemas de irrigação localizada (Franco \& Hernandez, 2009; Resende et al., 2001; Vieira et al., 2004); já a análise do risco de precipitação de $\mathrm{CaCO}_{3}$, por meio do índice de Langelier, revelou ausência de restrição ao uso para a maior parte das águas subterrâneas $(66,3 \%)$.

Os mapas produzidos por krigagem ordinária refletiram de forma satisfatória a dependência espacial das variáveis. Nas Figuras 4 e 5, se apresentam os mapas finais com a distribuição espacial das variáveis de qualidade das águas subterrâneas na bacia hidrográfica do Rio Piauí, segundo as classes de restrição ao uso para irrigação que permitem visualizar as regiões na bacia com predominância de riscos, bem como interpretar as possíveis causas para as concentrações detectadas. 
A.

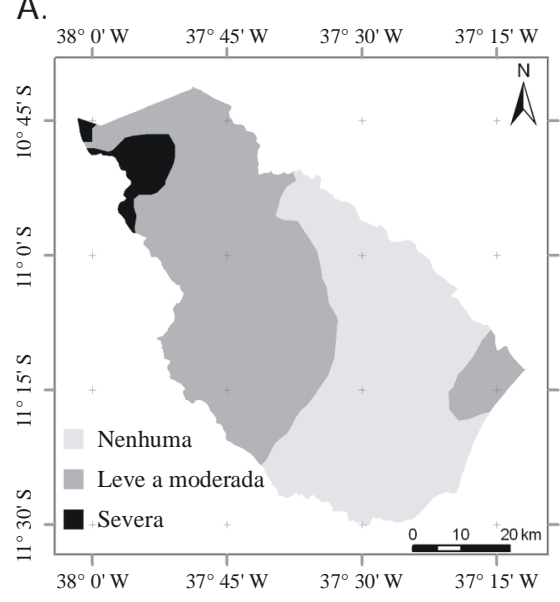

B.
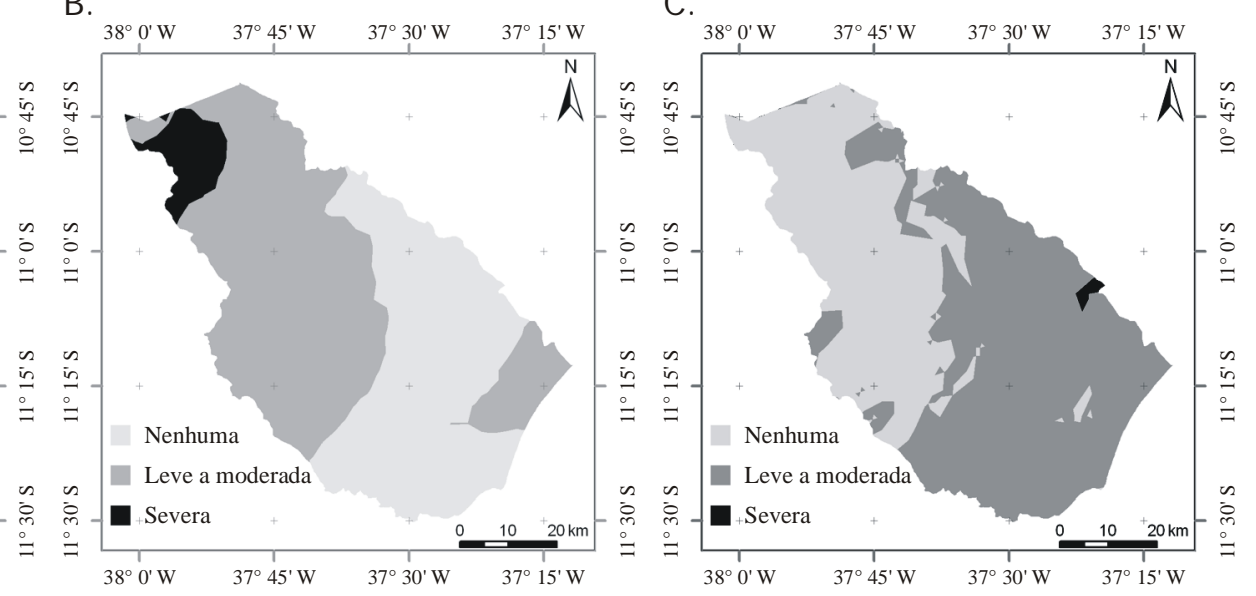

C.

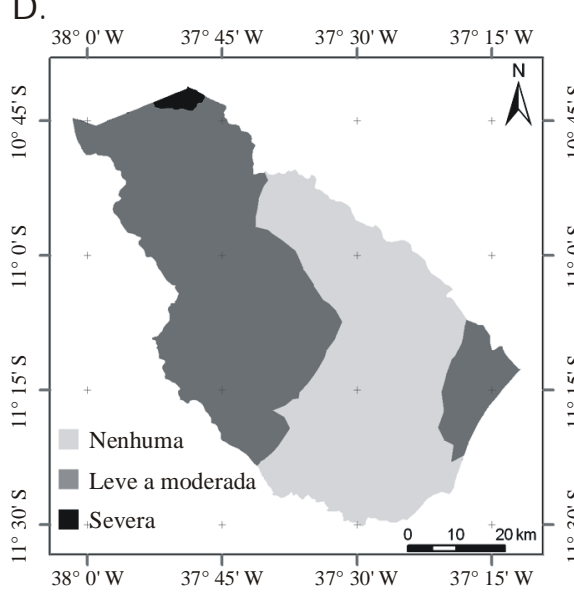

E.

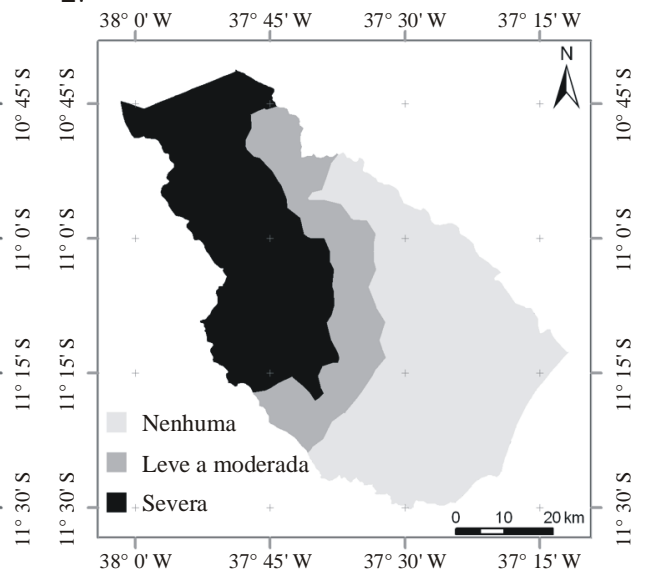

Figura 4. Distribuição espacial das variáveis de qualidade das águas subterrâneas na bacia hidrográfica do Rio Piauí, em Sergipe, segundo as classes de restrição ao uso associadas aos riscos de salinidade em relação à condutividade elétrica (A) e sólidos dissolvidos totais (B), de sodicidade relativos à RAS x CEa (C) e de toxicidade pelos íons sódio (D) e cloreto (E) para culturas irrigadas por superfície

Observa-se, para as variáveis CEa e SDT (Figura 4A e B), que o comportamento espacial é praticamente idêntico, com valores de restrição severa concentrando-se na porção noroeste da bacia e mudança gradual no sentido cabeceiras-foz. Na Figura 4C, nota-se que o risco de sodificação apresenta comportamento inverso ao da salinização, uma vez que aquele é avaliado com base na combinação RAS x CEa e valores elevados de outros sais, como cálcio e magnésio, podem reduzir o risco de sodificação. Assim, algumas regiões da bacia com águas de elevado risco em relação à salinização apresentaram nenhuma ou leve a moderada restrição relativa à sodificação; comportamento este que também foi observado por Andrade Júnior et al. (2006) e leva a uma concentração de poços com restrição ao uso, associada à sodificação dos solos na região centro-leste da bacia, do seu centro para a foz. O excesso de sais nesta porção da bacia reflete a composição do aquífero predominante na faixa agreste-semiárido, do tipo fissural, no qual os tempos de residência das águas armazenadas são bem elevados, favorecendo seu contato prolongado com o substrato componente da formação subterrânea.

Considerando-se, inicialmente, a toxicidade para culturas pelo uso da água em sistemas de irrigação por superfície (Figura 4D e E), verifica-se que houve maior predominân- cia de restrição severa ao uso das águas subterrâneas para o íon cloreto do que para o sódio, nas porções oeste da bacia; todavia, o comportamento espacial dessas variáveis variou pouco em relação aos sistemas de irrigação por aspersão (Figura 5A e B), verificando-se que a região centro-litoral da bacia concentra as áreas sem restrição ao uso, com exceção de uma pequena área próxima ao litoral, fato que pode estar relacionado a intrusões salinas nos poços próximos às praias; já a toxicidade decorrente da presença do íon $\mathrm{HCO}_{3}{ }^{-}$nas águas subterrâneas (Figura 5C), que quase não revelou restrição severa, apresentou zonas de restrição leve a moderada predominantes, que se aproximam mais do litoral na bacia, quando se compara à toxicidade apresentada pelos íons sódio e cloreo, o que pode ser justificado pela presença de pequenos aquíferos do tipo cárstico espalhados na região de predominância granular da bacia, possíveis de compor as águas explotadas em alguns poços.

A distribuição espacial dos graus de restrição ao uso da água relativos à obstrução em sistemas de irrigação localizada com relação ao pH (Figura 5D) permitiu verificar que uma pequena área com restrição severa se situa na porção norte da bacia, onde predominam as formações dos tipos cársticas e fissurais, com maior presença de sais, como carbonato, que podem elevar os valores de $\mathrm{pH}$; apenas uma re- 
A.

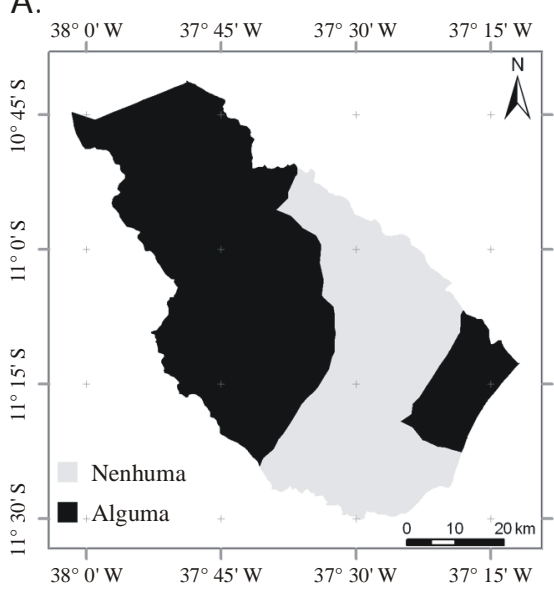

D.

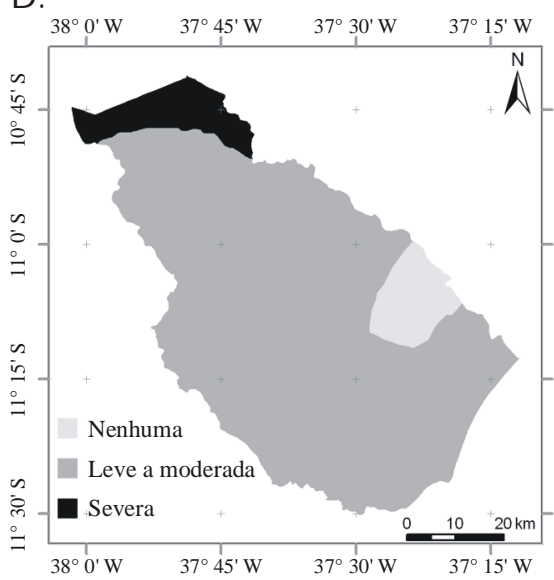

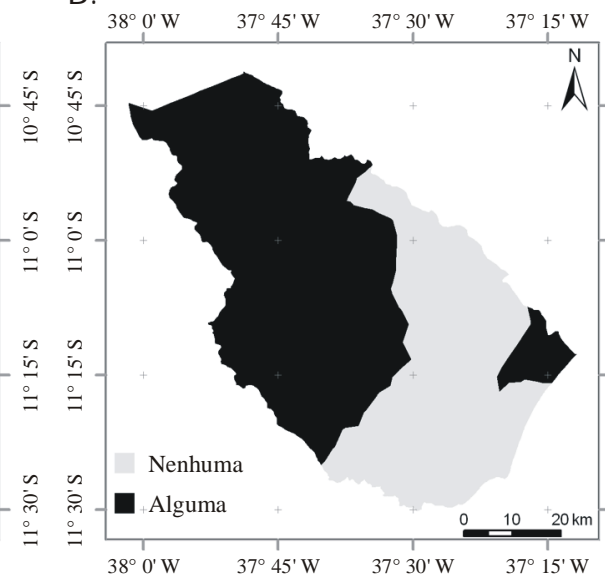

E.

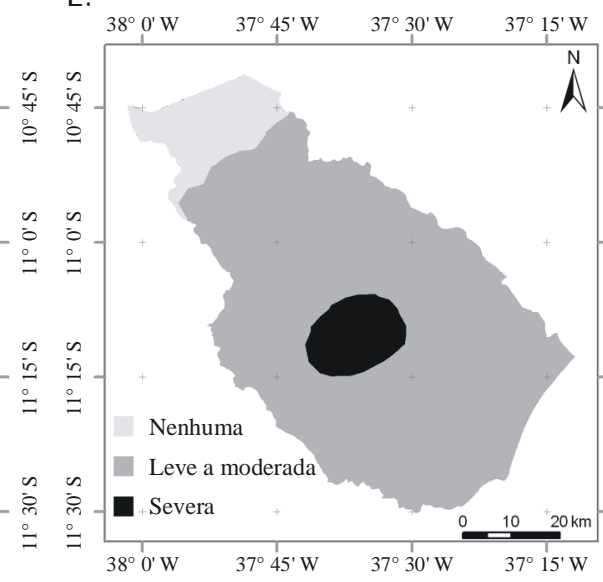

C.

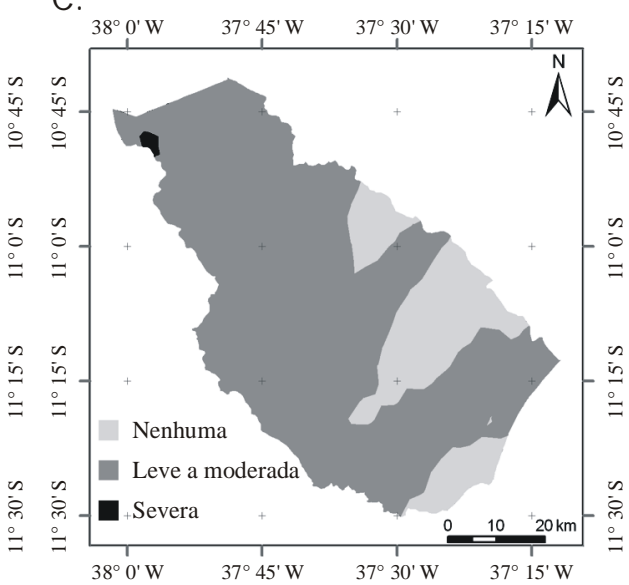

$\mathrm{F}$.

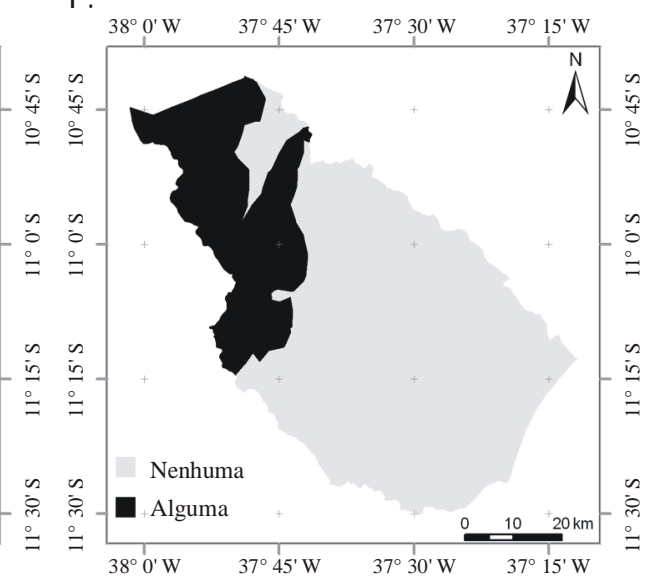

Figura 5. Distribuição espacial das variáveis de qualidade das águas subterrâneas na bacia hidrográfica do Rio Piauí, em Sergipe, segundo as classes de restrição ao uso associadas aos riscos de toxicidade pelos íons sódio (A), cloreto (B) e bicarbonato (C), para as culturas irrigadas por aspersão, e de obstrução em sistemas de irrigação localizada com relação a pH (D), ferro total $(E)$ e índice de Langelier (F)

gião localizada a centro-leste na bacia não apresenta restrição ao uso das águas subterrâneas, estando situada sobre o aquífero granular. Para a variável ferro total (Figura 5E), o comportamento foi diverso do das demais, com predominância de restrição leve a moderada em quase toda a bacia, exceto para uma área sem restrição localizada na porção norte e para uma pequena região com restrição severa, no centro da bacia. Há necessidade de estudos mais detalhados para esta variável, visto que apresentou a amostra com menor número de observações, dentre todas as variáveis, e cobertura deficitária sobre a área da bacia. Finalmente, para a restrição ao uso da água pelo risco de obstrução em sistemas de irrigação localizada devido à possibilidade de precipitação de cálcio, expressa pelo índice de Langelier (Figura 5F), nota-se que a porção centro-litorânea da bacia não apresentou restrição alguma. A restrição ao uso das águas subterrâneas para este risco se concentrou na porção noroeste da bacia, refletindo predominância de regiões cársticas e fissurais.

\section{CONCLUSÕES}

1. A análise espacial permitiu visualizar que regiões da bacia localizadas na porção centro-litorânea apresentam águas subterrâneas de melhor qualidade em relação à maioria das variáveis avaliadas, refletindo a presença dominante do aquífero granular.

2. As maiores restrições ao uso da água para irrigação se localizaram na porção norte da bacia, de domínio cristalino e predominância de clima semiárido.

3. Houve tendência de aumento na concentração de sais das águas subterrâneas no sentido centro-cabeceiras.

4. A aplicação da krigagem refletiu, de forma adequada, a influência da distribuição das formações aquíferas na qualidade das águas subterrâneas dos poços tubulares na bacia.

\section{LITERATURA CITADA}

Amorim, J. R. A. de; Resende, R. S.; Holanda, J. S. de; Fernandes, P. D. Qualidade da água na agricultura irrigada. In: Albuquerque, P. E. P. de; Durães, F. O. M. (ed.). Uso e manejo de irrigação. Brasília: Embrapa Informação Tecnológica, 2008. cap.6, p.255-316.

Andrade Júnior, A. S. de; Silva, E. F. F.; Bastos, E. A.; Melo, F. B.; Leal, C.M. Uso e qualidade da água subterrânea para irrigação no Semi-Árido piauiense. Revista Brasileira de Engenharia Agrícola e Ambiental, v.10, n.4, p.873-880, 2006. 
Ayers, R. S.; Westcot, D. W. Water quality for agriculture. 3rd. ed. Rome: FAO, 1994. 174p. FAO. Irrigation and Drainage Paper, 29.

Bomfim, L. F. C.; Costa, I. V. G. da; Benvenuti, S. M. P. Projeto cadastro da infra-estrutura hídrica do Nordeste: Estado de Sergipe. Aracaju: CPRM, 2002. http://www.cprm.gov.br/publique/ cgi/cgilua.exe/sys/start.htm?infoid=306\&sid=36. 9 Jun. 2008.

CPRM - Serviço Geológico do Brasil. Mapa de domínios e subdomínios hidrogeológicos do Brasil. 2007. http://mapoteca. cprm.gov.br/programas/carregando_mapa.php? script_map $=$ RecHidSub.map. 19 Set. 2008.

Cruz, W. B.; Melo, F. A. C. F. de. Zoneamento químico e salinização das águas subterrâneas do Nordeste do Brasil. Boletim de Recursos Naturais, v.7, n.1/4, p.7-40, 1969.

Franco, R. A. M; Hernandez, F. B. T. Qualidade da água para irrigação na microbacia do Coqueiro, Estado de São Paulo. Revista Brasileira de Engenharia Agrícola e Ambiental, v.13, n.6, p.772-780, 2009.

Hirata, R.; Suhogusoff, A.; Fernandes, A. Groundwater resources in the State of São Paulo (Brazil): The application of indicators. Anais da Academia Brasileira de Ciências, v.79, n.1, p.141-152, 2007.

Medeiros, J. F. de; Lisboa, R. de A.; Oliveira, M. de; Silva Júnior, M. J. da; Alves, L. P. Caracterização das águas subterrâneas usadas para irrigação na área produtora de melão da Chapada do Apodi. Revista Brasileira de Engenharia Agrícola e Ambiental, v.7, n.3, p.469-472, 2003.

Mélo, R. F. de; Coelho, R. D.; Teixeira, M. B. Entupimento de gotejadores convencionais por precipitados químicos de carbonato de cálcio e magnésio, com quatro índices de saturação de Langelier. Irriga, v.13, n.4, p.525-539, 2008.

Oliveira, F. M. de; Farias, S. A. R.; Ceballos, B. S. O. de; Azevedo, C. A. V. de; Gheyi, H. R.; Oliveira, A. K. de. Diagnóstico de qualidade das águas da microbacia do riacho Angico, para fins de irrigação. Revista Brasileira de Engenharia Agrícola e Ambiental, v.3, v.9, (Suplemento), p.221-225, 2005.
Porto, M. F. A.; Porto, R. L. L. Gestão de bacias hidrográficas. Revista Estudos Avançados, v.22, n.63, p.43-60, 2008.

Qadir, M.; Tubeileh A.; Akhtar, J.; Larbi, A.; Minhas, P. S.; Khan, M. A. Productivity enhancement of salt-affected environments through crop diversification. Land, Degradation \& Development, v.19, n.4, p.429-453, 2008.

Resende, R. S.; Casarini, E.; Folegatti, M. V.; Coelho, R. D. Ocorrência de entupimento de origem biológica em sistema de irrigação por gotejamento. Revista Brasileira de Engenharia Agrícola e Ambiental, v.5, p.156-160, 2001.

Ribeiro, T. A. P.; Airoldi, R. P. da S.; Paterniani, J. E. S.; Silva, M. J. M. da. Variação dos parâmetros físicos, químicos e biológicos da água em um sistema de irrigação localizada. Revista Brasileira de Engenharia Agrícola e Ambiental, v.9, n.3, p.295-301, 2005.

Rodrigues, J. O.; Andrade, E. M. de; Crisóstomo, L. A.; Teixeira, A. dos S. Modelos da concentração iônica em águas subterrâneas no Distrito de Irrigação Baixo Acaraú. Revista Ciência Agronômica, v.38, n.4, p.360-365, 2007.

Sergipe. Secretaria de Estado do Planejamento e da Ciência e Tecnologia. Superintendência de Recursos Hídricos. Atlas digital sobre recursos hídricos. Aracaju: SEPLANTEC/SRH, 2004. CD Rom.

Silva, V. de P. R. On climate variability in Northeast of Brazil. Journal of Arid Environments, v.58, n.4, p.575-596, 2004.

Silva Júnior, L. G. A.; Gheyi, H. R.; Medeiros, J. F. de. Composição química de águas do cristalino do Nordeste Brasileiro. Revista Brasileira de Engenharia Agrícola e Ambiental, v.3, n.1, p.11-17, 1999.

Smith, A. J. Rainfall and irrigation controls on groundwater rise and salinity risk in the Ord River Irrigation Area, northern Australia. Hydrogeology Journal, v.16, p.1159-1175, 2008.

Vieira, G. H. S.; Mantovani, E. C.; Silva, J. G. F.; Ramos, M. M.; Silva, C. M. Recuperação de gotejadores obstruídos devido à utilização de águas ferruginosas. Revista Brasileira de Engenharia Agrícola e Ambiental, v.8, n.1, p.1-6, 2004. 